\title{
LABORATÓRIO DE LOGÍSTICA: TESTANDO O TRADEOFF DE COMPRAS
}

\author{
Marco Aurélio Carino Bouzada \\ Universidade Estácio de Sá (Mestrado em Administração e Desenvolvimento Empresarial) \\ Av. Presidente Vargas, $642-22^{\circ}$. Andar - Centro - Rio de Janeiro (RJ) \\ marco.bouzada@estacio.br
}

\begin{abstract}
Resumo
Será que empresas que compram matéria-prima em maiores quantidades têm mesmo menores custos de aquisição e maiores custos de estocagem, como prega a teoria? Esta pesquisa teve como objetivo testar a relação entre o lote médio de aquisição, os custos de aquisição e de estocagem e o desempenho das empresas gerenciadas por participantes de um Jogo de Logística. Para testar a questão de pesquisa, foi realizada uma análise de correlação múltipla entre estas quatro variáveis. Os principais resultados (lotes maiores não impactando os custos de aquisição e de estocagem e nem o desempenho final das empresas) foram comparados às conclusões teóricas encontradas na literatura.

Palavras-Chaves: Jogos de Empresa; Logística; Laboratório de Logística; Compras; Tradeoff de Compras.
\end{abstract}

\begin{abstract}
Will companies which purchase raw material in larger quantities have lower acquisition costs and higher storage ones, like the theory says? This research aimed to test the relation among the average acquisition lot, acquisition and storage costs and the performance of enterprises managed by participants of a Logistics Business Game. To test the research question, it was conducted a multiple correlation analysis among these four variables. The main results (bigger lots not impacting acquisition and storage costs and final enterprises performance) were compared to theoretical conclusions found in the literature.
\end{abstract}

Keywords:

Business Games; Logistics; Logistics Laboratory; Procurement; Procurement Tradeoff. 


\section{INTRODUÇÃO}

Por se tratar de uma área de conhecimento muito ampla, genérica e dinâmica, a Administração de Empresas vem sofrendo diversas transformações ao longo dos últimos anos, em função das próprias pesquisas na área e das mudanças no panorama empresarial mundial. Desta maneira, tem-se tornado cada vez mais forte a necessidade de aprendizagem, treinamento e reciclagem para pesquisadores da área de Administração.

Existem diversas formas de conduzir pesquisas na área. No entanto, a metodologia de pesquisa a ser explorada neste trabalho procura inserir os envolvidos em um ambiente empresarial simulado: os Jogos de Empresas (Business Games). Tal formato, inclusive, necessita de mais pesquisas a seu respeito no país, para que possa se consolidar como uma efetiva metodologia de pesquisa no Brasil.

Mais especificamente, o "coração" desta proposta é o BR-LOG, um Jogo de Logística desenvolvido por Bouzada (2001).

Atualmente, existem alguns jogos de logística disponíveis no mercado doméstico, principalmente para fins de ensino e treinamento gerencial. No entanto, uma parcela muito reduzida deles é aplicada ao cenário brasileiro. Dentre estes, não foi possível descobrir algum em que as distâncias entre as localidades fossem verdadeiras e a disponibilidade dos modais fosse próxima da real. A maioria das aplicações utiliza localidades fictícias, o que exige uma boa capacidade de abstração. (LIMA, 2004; AZEREDO et al., 2006; CEL, 2008; BOUZADA, 2011)

Bonocielli Jr. e Lopes (2008) observam que muitos dos jogos de empresas utilizados no Brasil são adaptações de jogos importados de outros países.

Tais carências dificultam que tais opções viabilizem a efetiva pesquisa sobre Logística no Brasil. A captura de insights genéricos sobre o assunto até poderia ocorrer, mas a construção de conhecimento acerca das características específicas do mercado brasileiro ficaria prejudicada.

Além disso, a maioria dos jogos de logística existentes não contempla a possibilidade de transporte intermodal, a utilização dos modais aéreo e marítimo, a escolha da localização da(s) fábrica(s), a programação diária da produção, o transporte palletizado, o tratamento de produtos frigorificados, entre outros aspectos críticos da gestão logística de uma empresa. (LIMA, 2004; AZEREDO et al., 2006; CEL, 2008; BOUZADA, 2011)

A proposta geral, então, desta pesquisa consistiu em aplicar a metodologia intitulada "Laboratório de Logística" (BOUZADA, 2010) para testar elementos de pesquisa na área de Logística, já que ela é capaz de verificar experimentalmente diversas hipóteses de pesquisa e relacioná-las à teoria existente, confirmando-a ou refutando-a. Este é o propósito central do trabalho.

Dessa forma, teoria estaria sendo desenvolvida a partir de um método de simulação (o business game), como afirmam ser possível Davis, Eisenhardt e Bingham (2007).

O objetivo específico consistiu em testar se o tamanho médio do lote de aquisição de matérias-primas, o custo de aquisição e de estocagem e o próprio desempenho das empresas no jogo apresentam relação entre si.

\subsection{RELEVÂNCIA DA PESQUiSA}

Os benefícios da metodologia de ensino aqui pesquisada - Jogos de Empresas - se tornam ainda mais marcantes em áreas que envolvam raciocínio e manuseio de variáveis quantitativas, como a Logística. (BOUZADA, 2011)

Não há, deixe-se claro, a pretensão de sugerir que o simulador utilizado na pesquisa (o BR-LOG) é capaz de representar perfeitamente as condições do mercado brasileiro. $\mathrm{O}$ modelo não contempla todas as variáveis importantes e diversos parâmetros podem ir se desatualizando ao longo do tempo. Tal limitação pode ser reduzida com a adoção estrita do conceito de Laboratório de Gestão (SAUAIA, 2010), com os estudantes atualizando o modelo por meio de pesquisa aplicada conduzidas por eles em empresas reais. 
Mas a existência (e o reconhecimento) de tal limitação não invalida a possibilidade de o simulador utilizado (BR-LOG) ajudar a construir conhecimento acerca dos aspectos logísticos do mercado brasileiro, ainda mais quando comparado a outros simuladores logísticos mais genéricos e/ou menos realistas.

Até porque, similares aplicações de jogos de empresas, como a relatada por Oliveira e Alves (2012), demonstraram a aderência entre o ambiente simulado em um jogo e as características encontradas no mundo real, corroborando a tendência à adoção de simuladores organizacionais como instrumentos de pesquisa na área de Gestão.

\subsection{HIPÓTESES DE PESQUISA}

Desta forma, acredita-se que os resultados deste trabalho permitiram ajudar a verificar, entre outras coisas - em um ambiente simulado, onde o erro não acarreta consequências como no mundo real - se, conforme prega a teoria (BALLOU, 1993; BOWERSOX; CLOSS, 1996; GOMES; RIBEIRO, 2004), as empresas que adquirem matériaprima em grandes quantidades têm mesmo:

1. menores custos de aquisição; e

2. maiores custos de estocagem.

Adicionalmente, acredita-se que comprar matéria-prima em grandes quantidades não garanta melhor desempenho financeiro para a empresa, mas que também não implique, necessariamente, em piores resultados. A hipótese 3 de pesquisa fica, então, formalmente definida como: não há relação entre o tamanho do lote de aquisição de matéria-prima e o desempenho financeiro da empresa.

\section{REVISÃO DE LITERATURA}

Muitas vezes, pequenos lotes de compra são encomendados para satisfazer necessidades de produção. No entanto, uma das finalidades do estoque é permitir que menores preços possam ser obtidos na compra de mercadorias com o uso de lotes maiores que as demandas imediatas. (BALLOU, 1993)

$\mathrm{Na}$ determinação do lote econômico de compras, é importante levar em conta que, quanto maior o tamanho do lote, maior será o estoque médio e, consequentemente, maior será o custo de manutenção deste estoque, por unidade de tempo. No entanto, quanto maior este lote, menos ordens de compra são necessárias por unidade de tempo e, consequentemente, menor será o custo total de aquisição, pois menores serão os custos de pedidos e os custos unitários de aquisição, por causa dos descontos por quantidade usualmente praticados pelos fornecedores. (BOWERSOX; CLOSS, 1996; GOMES; RIBEIRO, 2004)

Os custos de manutenção de estoques e de aquisição têm comportamentos conflitantes. Quanto maiores as quantidades estocadas, maiores serão os custos de manutenção. Será necessária, entretanto, menor quantidade de pedidos, com lotes maiores, para manter os níveis de inventário, implicando em menores custos de aquisição. (BALLOU, 1993)

Se o desconto associado à quantidade adquirida for suficiente para compensar o custo adicional de manutenção de estoques, esta passa a ser uma alternativa viável. Tais descontos por quantidade costumam ocasionar maiores quantidades adquiridas, por encomenda. (BOWERSOX; CLOSS, 1996)

E a resposta para tal tradeoff, segundo Wanke e Fleury (1999), depende do segmento de negócio no qual está inserida a empresa, já que o valor agregado dos produtos e a magnitude da demanda são capazes de impactar essa relação. Os autores questionam em quais segmentos reduções no tamanho do lote não compensariam eventuais deseconomias de escala, ou seja, em que setores os custos associados à aquisição são significativamente superiores aos custos de manutenção de estoques, inviabilizando economicamente os regimes enxutos de ressuprimento. 
Em vista desta especificidade e por causa dos fatores que impactam a quantidade ideal a ser adquirida, Motta e Osório (2009) procuraram obter o lote ótimo de compras para diferentes situações em que variava a relação entre os custos de preparação do pedido e as taxas de encargos financeiros.

\section{METODOLOGIA}

A ideia consistiu em estabelecer um "Laboratório de Logística", uma estrutura de simulação de ambiente empresarial nos moldes do "Laboratório de Gestão" (SAUAIA, 2007, 2010), mas cujo motor foi o BR-LOG (BOUZADA; SALIBY, 2001), simulador contextualizado em um oligopólio onde empresas fabricam e tentam vender produtos fictícios, que diferem entre si em termos de magnitude e sazonalidade da demanda, preço, margem de lucro potencial e complexidade de produção, armazenagem e distribuição.

O jogo foi aplicado, durante os anos de 2011, 2012, 2013 e 2014 em:

$\checkmark$ quatro turmas de Especialização em Logística do COPPEAD/UFRJ, constituindo a própria disciplina, Jogo de Logística;

$\checkmark \quad$ três turmas de graduação em Administração da Escola Superior de Propaganda e Marketing (ESPM), nas suas três filiais (Rio de Janeiro, São Paulo e Porto Alegre), como parte integrante e como uma das formas de avaliação de disciplinas relacionadas a Logística Empresarial; e

$\checkmark \quad$ em quatro turmas do CBA em Logística (pós-gradução) do Instituto Brasileiro de Mercado de Capitias (IBMEC/RJ), constituindo a própria disciplina, Jogo de Logística.

Cabe deixar claro que o objetivo deste trabalho não consistiu em testar o simulador em ambiente de sala de aula, mas sim em usá-lo para testar elementos de pesquisa, conforme destacado na Introdução.

Também não se pretendeu, neste momento, que os participantes do jogo conduzissem pesquisa aplicada. Tal tipo de atividade é importante dentro do conceito mais amplo do Laboratório de Gestão (SAUAIA, 2010), mas pareceu mais oportuno considerá-la apenas em termos de oportunidades futuras.

Nas turmas da ESPM e do COPPEAD, a aplicação se deu de forma remota, com os participantes enviando suas decisões semanalmente por email para o aplicador, que rodou o simulador e devolveu os relatórios para as equipes, também semanalmente e por email. Os participantes precisaram usar algo em torno de 2 horas de computador semanais para tomar as decisões.

Nas turmas do IBMEC, a aplicação foi presencial, com o aplicador estando junto à turma durante as 15 horas divididas nas 5 aulas dedicadas à disciplina

Em todas as turmas, cada equipe fez uma apresentação, após o final do jogo, destacando a estratégia da empresa, como as tarefas foram divididas, os principais erros e acertos da equipe, as ferramentas de apoio utilizadas e qual foi o aprendizado resultante da atividade. Nesta apresentação, todos os integrantes de cada equipe tiveram que se manifestar oralmente.

Ao final das apresentações, o aplicador atribuiu uma nota individual para cada aluno, tentando refletir o seu nível de participação na atividade, a coerência das suas decisões e a intensidade do seu empenho.

Cada equipe também recebeu uma nota coletiva, refletindo simplesmente o desempenho financeiro da empresa administrada por ela.

A nota final de cada aluno na atividade foi obtida pelo cálculo da média aritmética entre a sua nota individual na apresentação (subjetiva) e a nota coletiva (objetiva).

Estes procedimentos encerraram a coleta de dados. Os mesmos foram tratados para atender os objetivos de pesquisa, conforme detalhado a seguir.

Para testar o "tradeoff de compras", ou seja, se o tamanho médio do lote de aquisição de matérias-primas é capaz de impactar de forma diferente alguns custos operacionais e o 
próprio desempenho das empresas no jogo, foi realizada uma análise de correlação linear múltipla (uma análise de correlação linear simples para cada par de variáveis), considerando, indistintamente, as empresas de todas as turmas que participaram do jogo. Os valores das quatro variáveis envolvidas na análise (totalizando, assim, seis correlações, duas variáveis a duas) foram coletados, para cada empresa, conforme especificado a seguir:

1. tamanho médio do pedido (toneladas) - total de toneladas encomendadas em todos os pedidos de matérias-primas dividido pela quantidade total de pedidos de matéria-prima;

2. custo de aquisição relativo (\%) - custo total de aquisição de matéria-prima de todas as encomendas dividido pelo faturamento total da empresa ao longo de todas as semanas;

3. custo de estocagem relativo $(\%)$ - custo total de estocagem de matéria-prima dividido pelo faturamento total da empresa ao longo de todas as semanas;

4. resultado final $(\mathrm{R} \$)$ - receita acumulada menos custo total acumulado ao longo de todas as semanas.

Os resultados dos testes foram comparados às conclusões teóricas e empíricas (mas não experimentais!) encontradas na literatura acerca dos elementos envolvidos na análise e da sua influência no mundo real, assim como fizeram Lima e Sauaia (2008) em relação ao impacto do investimento em P\&D nos resultados empresariais, Ribeiro (2012) quanto ao impacto de um bom planejamento da produção nos custos de produção, Lemos (2011) e Oliveira e Alves (2012) em relação ao impacto do preço na receita de vendas e no desempenho financeiro, Silva e Sauaia (2012) quanto ao impacto do cumprimento do Plano de Marketing na redução das incertezas e na melhoria do desempenho e Rivera, Domenico e Sauaia (2014) em relação à influência da heterogeneidade dos Times de Alta Gerência - em termos de valores individuais - no seu desempenho.

Por exemplo, de acordo com a teoria, espera-se, em princípio, que as empresas que compram matéria-prima em grandes lotes tenham custos de aquisição menores (hipótese de pesquisa 1) e custos de estocagem maiores (hipótese 2).

\section{RESULTADOS}

Os valores das variáveis descritas na seção anterior foram coletados para as empresas que participaram das 11 turmas mencionadas e estão apresentados na tabela 1 a seguir.

Como pode ser observado nos valores destacados em amarelo, algumas equipes de duas turmas da ESPM obtiveram alguns indicadores logísticos muito discrepantes dos demais. Acredita-se que isso tenha ocorrido em função de não ter havido um entendimento pleno do funcionamento do jogo por parte dos integrantes destas equipes. Em função disto, parece razoável eliminar da amostra as equipes 1 e 3 da turma 2 e as equipes 2 e 4 da turma 3 da da ESPM, de forma a evitar que seus dados poluam e comprometam a análise.

De posse dos dados das 37 empresas remanescentes da amostra, foi possível realizar a análise de correlação múltipla anteriormente mencionada e testar as hipóteses estabelecidas na seção 1.1 .

Os coeficientes de correlação linear de Pearson obtidos da análise podem ser observados na tabela 2 a seguir.

Em amarelo, está destacada a única correlação moderada positiva (entre 0,3 e 0,6); em azul, estão destacadas as correlações moderadas negativas (entre -0,3 e -0,6); as correlações fracas (abaixo de 0,3) não estão destacadas.

\subsection{RELAÇÃO ENTRE O TAMANHO MÉDIO DO PEDIDO E O CUSTO DE AQUISIÇÃO RELATIVO}

Esta relação pode ser visualizada graficamente na figura 1 a seguir.

É possível perceber uma completa falta de alinhamento entre as duas variáveis. Tal percepção é confirmada com a observação do coeficiente de correlação linear de Pearson $(r)$. 
O valor de 0,04 para $r$ indica ausência de correlação (abaixo de 0,3). Este valor não é estatisticamente diferente de zero, a 10\% de significância.

Tabela 1 - Tamanho médio do pedido, custos de aquisição e de estocagem relativos e resultado final das 41 empresas administradas pelos jogadores das 11 turmas

Fonte: elaboração própria

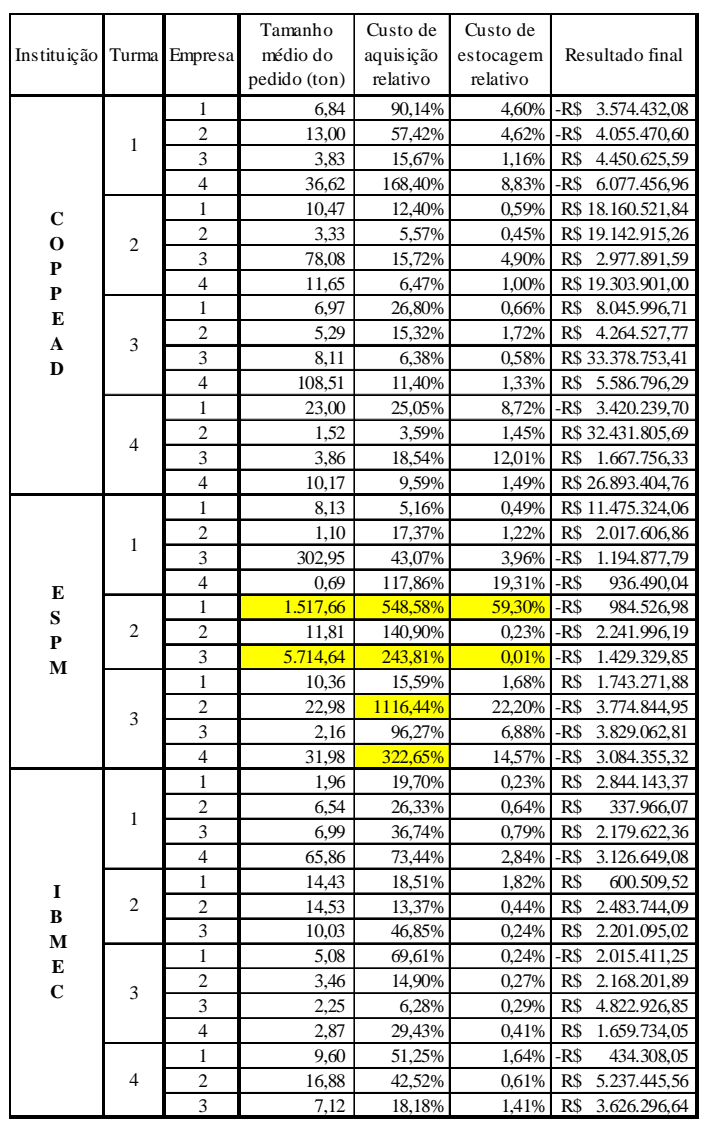

Tabela 2 - Coeficientes de correlação linear (r) entre tamanho médio do pedido, custos de aquisição e de estocagem relativos e resultado final das 37 empresas da amostra

\begin{tabular}{|l|r|r|r|}
\hline \multicolumn{1}{|c|}{$r$} & $\begin{array}{c}\text { Tamanho médio do } \\
\text { pedido (ton) }\end{array}$ & $\begin{array}{c}\text { Custo de aquisição } \\
\text { relativo }\end{array}$ & $\begin{array}{c}\text { Custo de } \\
\text { estocagem relativo }\end{array}$ \\
\hline Custo de aquisição relativo & 0,04 & & \\
\hline Custo de estocagem relativo & 0,07 & 0,48 & $-0,32$ \\
\hline Resultado final & $-0,16$ & $-0,54$ & \\
\hline
\end{tabular}

Fonte: elaboração própria

Em outras palavras, não é possível afirmar que, de uma maneira geral, as empresas que compraram em maiores quantidades obtiveram menores custos de aquisição, o que contribui para rejeitar a hipótese de pesquisa 1 - empresas que adquirem matéria-prima em grandes quantidades têm mesmo menores custos de aquisição.

\subsection{RELAÇÃO ENTRE O TAMANHO MÉDIO DO PEDIDO E O CUSTO DE ESTOCAGEM RELATIVO}

Esta relação pode ser observada na figura 2 a seguir.

Também neste caso, percebe-se uma falta de alinhamento. $\mathrm{O}$ valor de 0,07 obtido para $r$ confirma a ausência de correlação. Este valor não é estatisticamente diferente de zero, a $10 \%$ de significância.

Assim, não é possível afirmar que, de uma maneira geral, as empresas que compraram em maiores quantidades obtiveram maiores custos de estocagem, o que contribui 
para rejeitar a hipótese de pesquisa 2 - empresas que adquirem matéria-prima em grandes quantidades têm mesmo maiores custos de estocagem.

Figura 1 - Tamanho médio do pedido versus custo de aquisição relativo

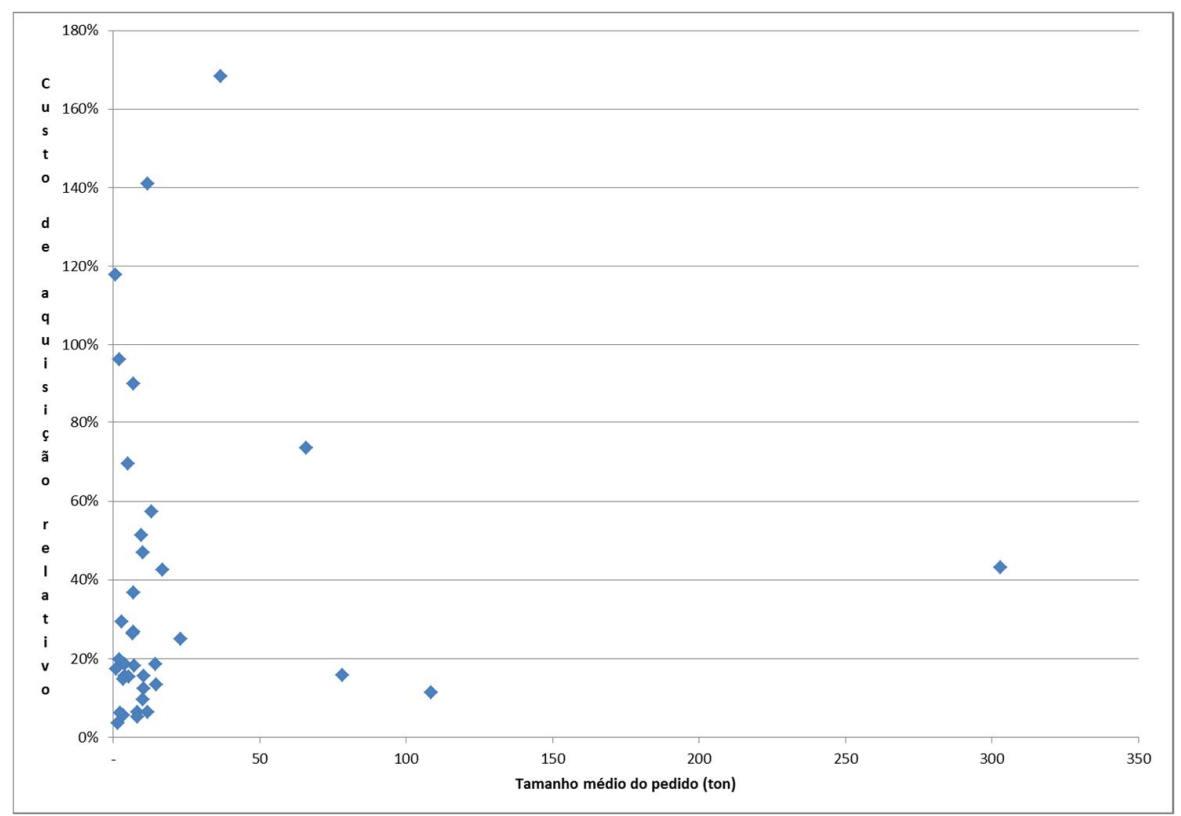

Fonte: elaboração própria

Figura 2 - Tamanho médio do pedido versus custo de estocagem relativo

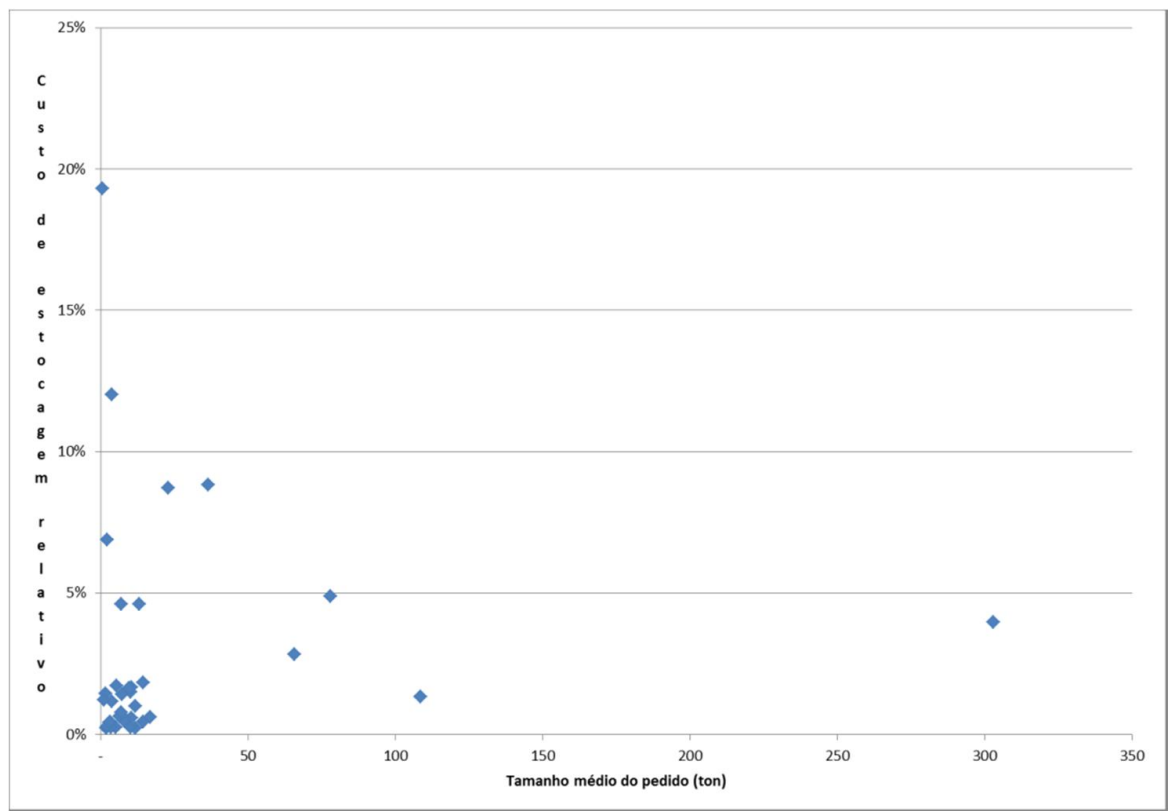

Fonte: elaboração própria

\subsection{RELAÇÃO ENTRE O TAMANHO MÉDIO DO PEDIDO E O RESULTADO FINAL}

A figura 3 a seguir evidencia essa relação.

Novamente pode-se observar uma relação nebulosa entre as variáveis. O coeficiente $r$ apresentou valor de $-0,16$, o que caracteriza uma correlação negativa, mas fraca. Este valor não é estatisticamente diferente de zero, a $10 \%$ de significância.

Desta forma, não é possível afirmar que as empresas que compraram em maiores quantidades obtiveram melhores nem piores desempenhos no jogo, o que contribui para 
confirmar a hipótese de pesquisa 3 - não há relação entre o tamanho do lote de aquisição de matéria-prima e o desempenho financeiro da empresa.

Figura 3 - Tamanho médio do pedido versus resultado final

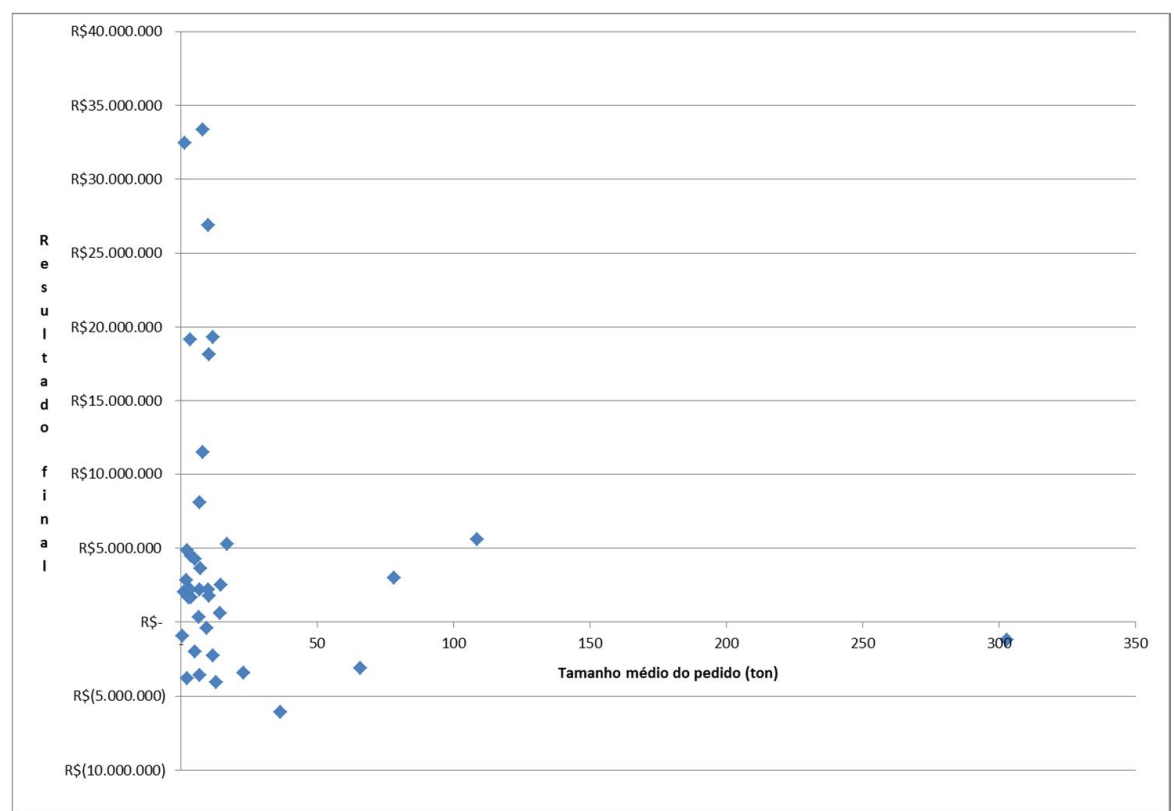

Fonte: elaboração própria

\subsection{RELAÇÃO ENTRE O CUSTO DE AQUISIÇÃO RELATIVO E O CUSTO DE ESTOCAGEM RELATIVO}

A figura 4 a seguir viabiliza a visualização desta relação.

\section{Figura 4 - Custo de aquisição relativo versus custo de estocagem relativo}

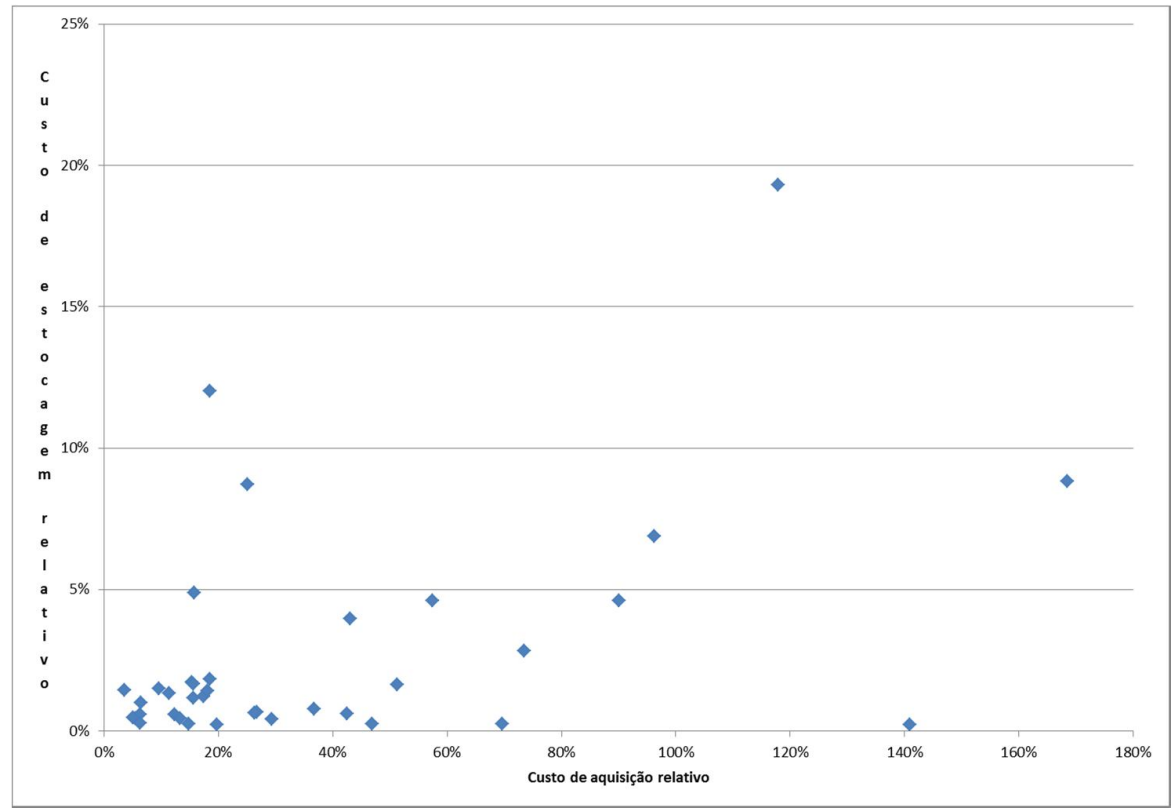

Fonte: elaboração própria

Neste caso, é nítido um alinhamento mais acentuado entre as variáveis do que nas situações anteriores. Tal percepção é confirmada com o valor obtido para $r$ : 0,48 , indicando uma correlação positiva moderada (entre 0,3 e 0,6). Este valor é estatisticamente diferente de zero, a $1 \%$ de significância. 
Por conseguinte, é possível afirmar que, de uma maneira geral e com moderada convicção, as empresas que tiveram custos de aquisição maiores também obtiveram custos de estocagem maiores.

\subsection{RELAÇÃO ENTRE O CUSTO DE AQUISIÇÃO RELATIVO E O RESULTADO FINAL}

Esta relação pode ser observada na figura 5 a seguir.

Figura 5 - Custo de aquisição relativo versus resultado final

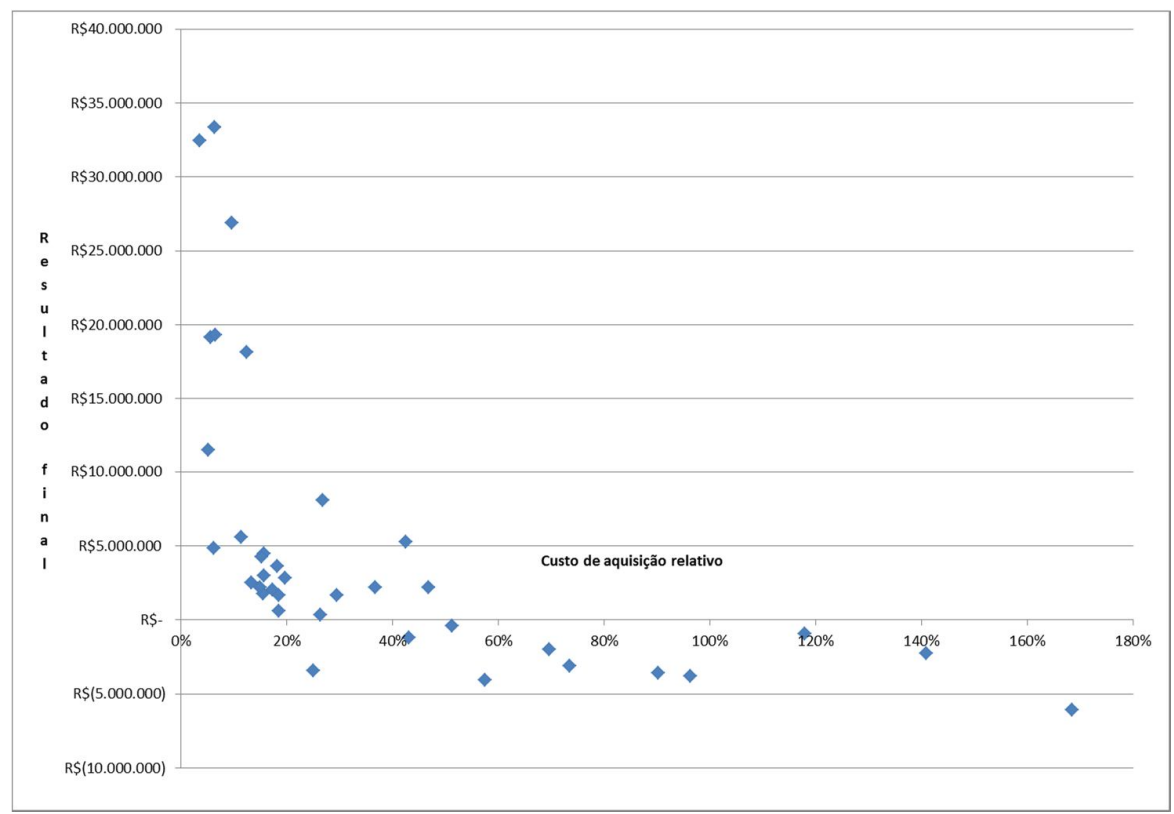

Fonte: elaboração própria

O alinhamento neste caso também parece bem definido, mas desta vez de forma inversa, ou seja, com uma variável diminuindo quando a outra aumenta. O sinal obtido para $r$ confirma essa expectativa e o seu valor, $-0,54$, sugere uma correlação negativa moderada (entre 0,3 e 0,6). Este valor é estatisticamente diferente de zero, a $1 \%$ de significância.

Ou seja, é possível afirmar que, de uma maneira geral e com moderada convicção, as empresas que tiveram custos de aquisição maiores alcançaram piores desempenhos no jogo.

\subsection{RELAÇÃO ENTRE O CUSTO DE ESTOCAGEM RELATIVO E O RESULTADO FINAL}

A figura 6 a seguir fornece subsídios sobre essa relação.

O alinhamento também é inverso, como no caso anterior, mas razoavelmente menos marcante. $\mathrm{O}$ valor de $r$ de $-0,32$ também implica em uma correlação negativa moderada, mas menos acentuada. Este valor também é estatisticamente diferente de zero, mas a $10 \%$ de significância.

É possível afirmar que, de uma maneira geral e com moderada convicção, as empresas que tiveram maiores custos de estocagem conseguiram piores desempenhos no jogo.

\section{CONSIDERAÇÕES FINAIS}

Este trabalho procurou fazer uso de uma metodologia tipicamente de ensino (os Jogos de Empresas) para servir de palco experimental para pesquisa, em uma tentativa de verificar ou refutar teoria na área de Logística.

As variáveis tamanho médio do pedido, custo de aquisição relativo, custo de estocagem relativo e resultado final de empresas virtuais participantes de onze aplicações de um jogo de Logística em turmas de graduação e pós-graduação foram utilizadas como dados experimentais para verificar algumas relações entre estas variáveis, que a teoria prega existir, e testar três hipóteses de pesquisa. 


\section{Figura 6 - Custo de estocagem relativo versus resultado final}

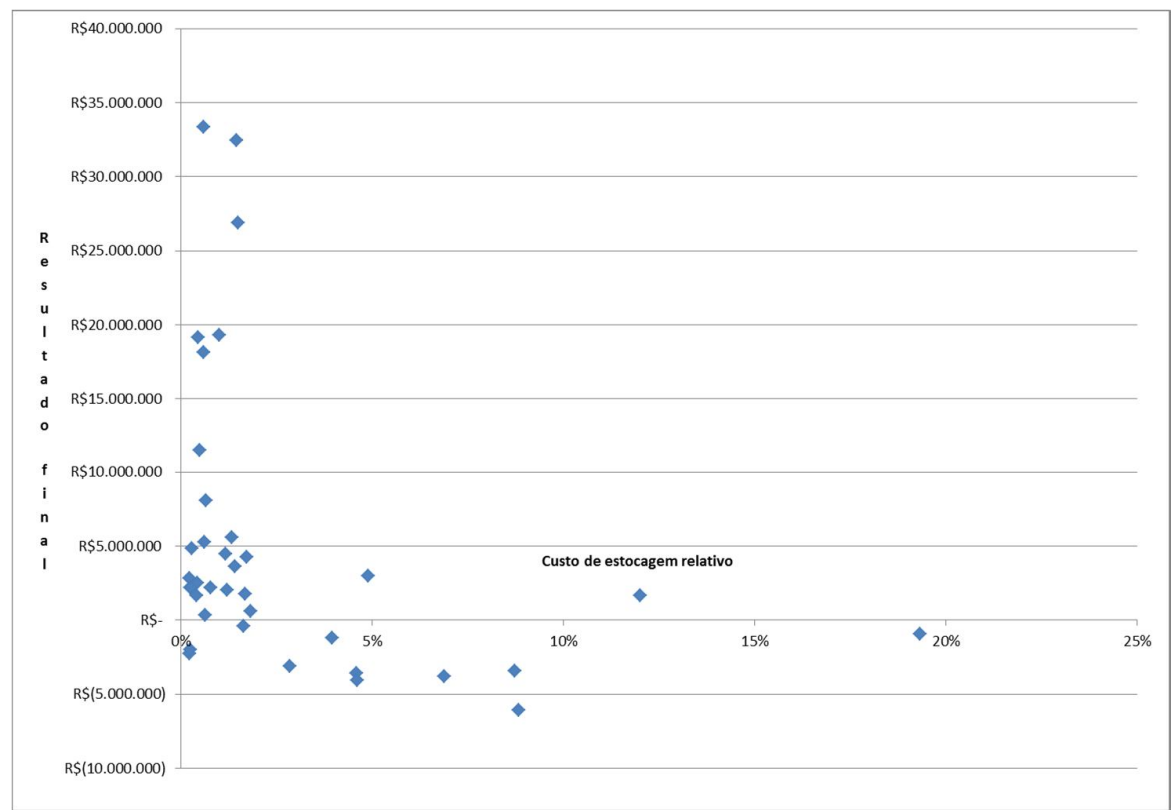

Fonte: elaboração própria

A hipótese 1 - empresas que adquirem matéria-prima em grandes quantidades têm mesmo menores custos de aquisição - foi rejeitada. Este resultado empírico vai de encontro ao que dizem Ballou (1993) sobre a possibilidade de obtenção de menores preços na compra de mercadorias com o uso de lotes maiores de aquisição e Bowersox e Closs (1996) e Gomes e Ribeiro (2004) sobre a necessidade de uma menor quantidade de ordens de compra, quando os lotes são maiores, acarretando menores custos de aquisição, pois menores seriam os custos de pedidos e os custos unitários de aquisição, por causa dos descontos por quantidade usualmente praticados pelos fornecedores.

A hipótese 2 - empresas que adquirem matéria-prima em grandes quantidades têm mesmo maiores custos de estocagem - também foi rejeitada. Este resultado contraria Bowersox e Closs (1996) e Gomes e Ribeiro (2004), que afirmam que quanto maior o tamanho do lote, maior será o estoque médio e, consequentemente, maior será o custo de manutenção deste estoque, por unidade de tempo.

Já a hipótese 3 - não há relação entre o tamanho do lote de aquisição de matériaprima e o desempenho financeiro da empresa - foi confirmada.

Wanke e Fleury (1999) dizem que as considerações sobre esse tradeoff do tamanho do lote de aquisição dependem do segmento do negócio. Já Motta e Osório (2009) destacam a especificidade do segmento e os fatores que impactam a quantidade ideal a ser adquirida. Em outras palavras, todos estes autores sugerem não haver uma relação óbvia entre o tamanho do lote e o desempenho da empresa, válida para qualquer caso. Caso contrário, haveria uma sugestão implícita de existência de uma estratégia vencedora, de maximização do resultado da empresa. E, se assim fosse, todas as empresas tentariam praticar essa estratégia, maximizando ou minimizando o lote de compras. E isso, obviamente, não é o que ocorre na realidade.

Assim, de certa forma, a confirmação da última hipótese de pesquisa vai ao encontro do que dizem estes últimos autores destacados.

Além das relações presentes nas hipóteses de pesquisa, outras três foram testadas. A relação entre os custos relativos de aquisição e estocagem revelou-se positivamente moderada, o que contraria parcialmente Ballou (1993), que afirma que os custos de manutenção de estoques e de aquisição têm comportamentos conflitantes.

Já a relação entre o resultado final da empresa e seus custos relativos de aquisição e estocagem se mostrou moderadamente negativa, em ambos os casos. Como o custo é um 
componente muito influente no desempenho final das empresas no jogo, era mesmo de se esperar que menores custos implicassem em melhores resultados.

Naturalmente, os resultados deste trabalho precisam ser vistos com as devidas ressalvas, já que um jogo de empresas depende de um simulador, que: (i) se aplica a um contexto específico de produtos, matérias-primas e dinâmicas de concorrência, podendo, eventualmente, ter pouca representatividade no contexto analisado; e (ii) é construído em cima de modelo que, por sua vez, nunca deixa de ser uma simplificação da realidade, em função de não contemplar - tanto por conveniência do algoritmo quanto por questões de parcimônia - muitas variáveis relevantes.

Além disso, as empresas participantes das aplicações do jogo foram geridas por alunos (com maior ou menor grau de experiência na área), muitos deles de graduação, e não por profissionais extremamente experientes na área de Logística. Desta forma, seria muito leviano afirmar que os resultados seriam exatamente os mesmos se as decisões que impactam os indicadores estudados tivessem sido tomadas por profissionais de mercado pertencentes a empresas reais, o que caracterizaria uma pesquisa empírica, e não experimental, como foi a relatada neste artigo.

Não obstante, os resultados experimentais aqui apresentados podem e devem ser lavados em conta, pois lançam uma luz a respeito de alguns modelos teóricos, ora verificando-os, ora refutando-os, contribuindo para um melhor entendimento dos mesmos, mas nunca tendo a pretensão de serem definitivos acerca de tais fenômenos.

Além disso, estes resultados, especialmente os que refutam as hipóteses teóricas, podem servir de inspiração para ideias e abrir portas para estudos futuros capazes de, por exemplo, verificar mais detalhadamente a relação entre o tamanho do lote e o custo de estocagem para entender o motivo de compras em grandes lotes não terem implicado em menores custos de estocagem; ou ainda, identificar em que situações custos de aquisição e de estocagem podem não caminhar em sentidos opostos, como ocorreu na pesquisa apresentada neste artigo.

Outra sugestão para trabalhos futuros consiste em dar continuidade ao Laboratório de Logística para testar experimentalmente mais alguns elementos de pesquisa na área de Logística, conforme sugeridos por Bouzada (2010).

\section{REFERÊNCIAS BIBLIOGRÁFICAS}

[1] AZEREDO, S.; ORNELLAS, A.; RAMOS, R. Jogos de empresas aplicados à logística empresarial: um panorama dos modelos disponíveis no país. In: ENCONTRO NACIONAL DE ENGENHARIA DE PRODUÇÃO, 26., 2006, Fortaleza. Anais... Fortaleza: ENEGEP, 2006.

[2] BALLOU, R. Logística Empresarial. São Paulo: Atlas, 1993.

[3] BONOCIELLI Jr., S.; LOPES, P. Estudo e Modelagem do Mercado de Capitais em Jogo de Empresas Geral. In: SEMINÁRIOS EM ADMINISTRAÇÃO, 11., 2008, São Paulo. Anais... São Paulo: SEMEAD, 2008.

[4] BOUZADA, M. Um jogo de Logística genuinamente brasileiro. Dissertação (Mestrado em Administração) - Instituto de Pós-Graduação e Pesquisa em Administração. Rio de Janeiro: UFRJ/COPPEAD, 2001.

[5] BOUZADA, M. Laboratório de logística: uma proposta de metodologia de pesquisa. In: SIMPÓSIO DE ADMINISTRAÇÃ̃O DA PRODUÇÃO, LOGÍSTICA E OPERAÇÕES INTERNACIONAIS, 13., 2010, São Paulo. Anais... São Paulo: SIMPOI, 2010.

[6] BOUZADA, M. (Org.). Jogando Logística no Brasil. Curitiba: CRV, 2011.

[7] BOUZADA, M.; SALIBY, E. Um Jogo de Logística genuinamente brasileiro. In: SIMPÓSIO DE PESQUISA OPERACIONAL E LOGÍSTICA DA MARINHA, 4., 2001, Rio de Janeiro. Anais... Rio de Janeiro: SPOLM, 2001. 
[8] BOWERSOX, D., CLOSS, D. Logistical management: the integrated supply chain process. New York: McGraw-Hill, 1996.

[9] CEL. Centro de Estudos em Logística do COPPEAD/UFRJ. Jogos de Empresas. Disponível em: <http://www.centrodelogistica.org/new/fs-jogos.htm>. Acesso em: 30 jun. 08

[10] DAVIS, J.; EISENHARDT, K.; BINGHAM, C. Developing theory through simulation methods. Academy of Management Review, v. 32, n. 2, p. 480-499, 2007.

[11] GOMES, C.; RIBEIRO, P. Gestão da Cadeia de Suprimentos Integrada à Tecnologia da Informação. São Paulo: Pioneira Thomson Learning, 2004.

[12] LEMOS, M. Decisões de preço em jogos de empresas: o estudo das elasticidades e do ponto de equilíbrio como ferramentas de apoio à decisão. Revista LAGOS - UFF (Volta Redonda), v. 1, n. 2, p. 1-16, 2011.

[13] LIMA, M. Jogos de empresa e operações logísticas. Artigos CEL, 2004. Disponível em: <http://www.cel.coppead.ufrj.br/fr-art-jogos_empresa.htm>. Acesso em: 30 jun. 08.

[14] LIMA, M.; SAUAIA, A. Impacto dos Investimentos em P\&D nos Resultados Empresariais: um Estudo Laboratorial com Jogos de Empresas. In: SIMPÓSIO DE GESTÃO DA INOVAÇÃO TECNOLÓGICA, 25., 2008, Brasília. Anais... Brasília: ANPAD, 2008.

[15] MOTTA, F.; OSÓRIO, W. COMPARAÇÃO DE NÍVEIS DE ESTOQUES DETERMINADOS POR DUAS DIFERENTES POLÍTICAS DE REPOSIÇÃO: ESTUDO-DE-CASO EM EMPRESA DE PAINÉIS ELÉTRICOS. Revista Administração - Faculdades Network, v. 3, n. 1, p. 1-9, 2009.

[16] OLIVEIRA, M.; ALVES, C. Política de Preços no Desempenho de Empresas: um Estudo com Simulador Organizacional de Estratégia. Sociedade, Contabilidade $\boldsymbol{e}$ Gestão, v. 7, n. 1, p. 140-155, 2012.

[17] RIBEIRO, R. Planejamento da produção para atender a demanda com minimização de custos em um jogo de empresas. In: SEMINÁRIOS DE ADMINISTRAÇÃO DA USP, 15., 2012, São Paulo. Anais... São Paulo: SEMEAD, 2012.

[18] RIVERA, J.; DOMENICO, S.; SAUAIA, A. Influência da Dissimilaridade de Valores Individuais no Resultado de Times de Alta Gerência: um estudo em laboratório de gestão. Revista Brasileira de Gestão de Negócios, São Paulo, v. 16, n. 50, p. 60-74, jan./mar. 2014.

[19] SAUAIA, A. Workshop em Jogos de Empresas: uma vivência para coordenadores, docentes e pesquisadores. In: ENCONTRO DE ENSINO E PESQUISA EM ADMINISTRAÇÃO E CONTABILIDADE, 1., 2007, Recife. Anais... Recife: ANPAD, 2007.

[20] SAUAIA, A. Laboratório de gestão: simulador organizacional, jogo de empresas e pesquisa aplicada. 2 ed. Barueri: Manole, 2010.

[21] SILVA, S.; SAUAIA, A. Avaliação do Previsto X Realizado num Jogo de Empresas. In: CONGRESSO DE ADMINISTRAÇÃO, SOCIEDADE E INOVAÇÃO, 1., 2012, Volta Redonda (RJ). Anais... Volta Redonda (RJ): CASI, 2012.

[22] WANKE, P.; FLEURY, P. O Paradigma do Ressuprimento Enxuto: Armadilha na Gestão do Fluxo de Materiais Entre Elos da Cadeia de Suprimentos. In: ENCONTRO DA ASSOCIAÇÃO NACIONAL DE PÓS-GRADUAÇÃO E PESQUISA EM ADMINISTRAÇÃO, 23., 1999, Foz do Iguaçu (PR). Anais... Foz do Iguaçu: ANPAD, 1999. 